\title{
Synergistic Effects of 4-Aminopyridine and Paclitaxel on MCF 7 Cell Line
}

\author{
Esra M. Cuce Aydogmus (10), Gunseli Ayse Inhan Garip \\ Marmara University, School of Medicine, Biophysics Dept \\ Correspondence Author: Esra M. Cuce Aydogmus \\ E-mail: esracuce@gmail.com \\ Received: $26.04 .2019 \quad$ Accepted: 01.07 .2019
}

\begin{abstract}
Objectives: Aim of this study is to increase the effectiveness of paclitaxel (PTX) with the use of 4 - aminopyridine (4-AP) on breast cancer cell line MCF-7.

Methods: In this study, L-929 (ATCC CRL-6364) and MCF-7 (ATCC - HTB 22) cell lines were used. IC50 and survival values were determined by trypan blue exclusion; cell cycle analysis was determined by measuring levels of $\mathrm{Cdk2}$ and Histone $(\mathrm{H} 3)$ and plasma membrane potential (Vm) measurements were performed using fluorescent Bis-(1,3-dibutylbarbituric acid) trimethine oxonol (DiBaC4(3)).

Results: IC50 values were determined for two agents and these values were combined. Combination treatments ie. "4-AP (4 mM) + PTX (5 nM)" and "4-AP ( $4 \mathrm{mM})+$ PTX $(7.5 \mathrm{nM})$ " decreased viability $17 \% \pm 8.08$ and $45 \% \pm 3.18$, respectively for L-929 cells and decreased viability $60 \% \pm 3.7$ and $74 \% \pm 2.6$, respectively for MCF-7 cells. For L-929 cells, plasma membrane potential measurements resulted in depolarization for 4-AP, PTX (5 nM) and PTX (7.5 nM), and resulted in hyperpolarization for the combinations. For MCF-7 cells, plasma membrane potential measurements resulted in depolarization for 4-AP, PTX (7.5 nM) and 4-AP + PTX ( $5 \mathrm{nM})$, and resulted in hyperpolarization for PTX (5 nM) and 4-AP + PTX (7.5 nM). Changes of Cdk2 and H3 levels showed mostly G1 arrest for MCF 7 cells and G2/M arrest for L-929 cells.

Conclusions: Combination treatments increased the cell death for MCF-7 cells. But, combination treatments didn't show synergistic effect on L-929 which is accepted as a non-cancerous cell. These data showed that use of 4-AP in combination with the anticancer agent paclitaxel is a promising approach for cancer treatment.

Keywords: 4 - aminopyridine, paclitaxel, MCF-7 breast cancer cell line.
\end{abstract}

\section{INTRODUCTION}

The prevalence of breast cancer among women worldwide is $10.4 \%$, the most common type of cancer after lung cancer (1). Breast cancer consists of 3 major tumor subtypes categorized according to estrogen or progesterone receptor expression and ERBB2 gene amplification. The 3 subtypes have distinct risk profiles and treatment strategies (2).

Paclitaxel (PTX, Taxol) a pseudoalkaloid that has a taxane ring was first isolated from the extract of the inner bark of Pacific Yeast (Taxus brevifolia) in 1969 and identified in 1971. Since its acceptance as a chemotherapeutic drug by the FDA for ovarian cancer in 1973 and for breast cancer in 1974 (3) it has been widely used for ovarian, breast, non-small cell lung cancer, head and neck tumors, Kaposi's sarcoma and urologic malignancies (4). The main mechanism by which paclitaxel suppresses cell proliferation and promotes cell death is by its action on microtubule dynamics. It is effective during the mitosis phase and the $\mathrm{G} 2 / \mathrm{M}$ transition by promoting the polymerization of microtubules and thus interfering with the mitotic assembly and chromatid separation (5). Paclitaxel belongs to the family of microtubule targeting drugs. Due to its effect on mitosis it is categorized as a mitotic inhibitor or a mitosis poison. PTX blocks cell cycle at G2/M and thus causes cell death by activating Spindle Assembly Checkpoint (SAC). Mitotic arrest results in either death during mitosis or an abnormal exit from mitosis, without chromosome segregation or cytokinesis, to form a tetraploid G1 cell; this exit is known as mitotic slippage. After slippage, cells can die, arrest, or continue cycling (6).

Ion channels are responsible for the control of essential parameters in cell homeostasis like cell volume, intracellular $\mathrm{pH}$, membrane potential and cell death (7). Potassium $\left(\mathrm{K}^{+}\right)$channels that form the largest family of ion channels are subdivided into voltage gated $\mathrm{K}^{+}$channels, calcium $\left(\mathrm{Ca}^{+2}\right)$ activated potassium channels and so on. Potassium channels have often been implicated in the control cell cycle progression and are frequently seen to be mutated in neoplastic cells. Due to this they are considered to be potential targets for therapy. A substantial amount of research has revealed decreased proliferation and cell death by blocking $\mathrm{K}^{+}$channels (8).

4-aminopyridine (4-AP) is a voltage gated $\mathrm{K}^{+}$channel blocker that causes depolarization of the cell. It is usually used to relieve neurological symptoms in patients with multiple sclerosis and chronic spinal cord injury (9). On the other hand, 4-AP has also been seen to have pro-apoptotic properties and 
suppress proliferation at commonly used concentrations (10, $11,12)$ although there are reports that show anti apoptotic effects of 4-AP (13). 4-AP arrests cell cycle at G1 phase (10). It has been demonstrated that membrane potential $(\mathrm{Vm})$ fluctuates during the cell cycle $(14,15)$. Cancerous cells are more depolarized facilitating the G0/G1 transition and hyperpolarizing $V m$ is necessary at G1/S transition. It is probable that 4-AP by depolarizing $\mathrm{Vm}$ causes arrest at $\mathrm{G} 1$ phase, ultimately leading to cell death (12).

The present work aimed to determine the effect of PTX and 4-AP combination on breast cancer cell line MCF-7. The rationale for this study was that PTX and 4-AP causes arrest at different phases of cell cycle and thus would act synergistically. Cell cycle phase determination by $\mathrm{Cdk} 2$ and $\mathrm{H} 3$ measurements as well as survival and membrane potential measurements were conducted to gain insight into the mechanism of this combination. It is expected that these results would prove to be beneficial for a new combination therapy for breast cancer.

\section{MATERIALS AND METHODS}

\subsection{Materials}

MCF-7 and L-929 cell lines were a kind gift from Assoc. Prof. Dr. Oya Orun. HBSS, 4 - AP and PTX were purchased from Sigma-Aldrich (Taufkirschen, Germany). DiBaC4(3) [Bis-(1,3dibutylbarbituric acid) trimethine oxonol] was purchased from AAT Bioquest (California, USA). Cell cycle in cell Elisa kit was purchased from Abcam (Cambridge, UK). DMEM, FBS, Antibiotic and L glutamine were purchased from Capricorn scientific (Ebsdorfergrund, Germany). Synergy H1 Microplate reader was purchased from Biotek (Bad Friedrichshall, Germany).

\subsection{Cell lines and cell culture}

In this study, L-929 (ATCC CRL-6364) and MCF-7 (ATCC - HTB 22) cell lines were used. L-929 fibroblast mouse cell line was used as healthy cell, estrogen receptor positive (ER+) MCF-7 that was derived from a metastatic site was used as cancer cell line.

All cell lines were grown in DMEM medium containing $10 \% \mathrm{FBS}, 1 \%$ antibiotics $(50 \mathrm{U} / \mathrm{mL}$ penicillin and $50 \mathrm{ug} / \mathrm{mL}$ streptomycin) and $2 \mathrm{mM} \mathrm{L}$ glutamine in $\mathrm{CO}_{2}$ incubator $\left(37^{\circ}\right.$ C, $5 \% \mathrm{CO}_{2}$ ). For survival determination, cells were seeded in 6 -well plates as $1.8 \times 10^{5}$ cells/well in $3 \mathrm{~mL}$ growth medium to achieve confluency.

\subsection{Cytotoxicity}

4-AP stock solution was prepared in DMSO. Cells were seeded in 6-well plates and treated with five different concentrations of 4-AP and incubated in $\mathrm{CO}_{2}$ incubator $\left(5 \% \mathrm{CO}_{2}, 37^{\circ} \mathrm{C}\right)$ for 24 hours. After treatment, cells were trypsinized and counted with trypan blue dye on hemocytometer.

PTX stock solution was prepared in DMSO. Cells were seeded in 6-well plates and treated with seven different concentrations of PTX and incubated in $\mathrm{CO}_{2}$ incubator $\left(5 \% \mathrm{CO}_{2}, 37^{\circ} \mathrm{C}\right)$ for 24 hours. After treatment, cells were trypsinized and counted with trypan blue dye on hemocytometer (16).

Combination assay was performed as indicated: 4-AP $\mathrm{IC}_{50}$ value $(4 \mathrm{mM})$ was taken and combined with two different values of PTX; $\mathrm{IC}_{50}$ concentration and a concentration lower than the $\mathrm{IC}_{50}$ concentration 1. PTX (7.5 nM) and 2. PTX (5 nM).

Cells were seeded in 6-well plates and treated with 4-AP and PTX together for 24 hours in $\mathrm{CO}_{2}$ incubator. After treatment, cells were trypsinized and counted with trypan blue dye on haemocytometer.

\subsection{Plasma membrane potential measurement}

DiBaC4(3) [Bis-(1,3-dibutylbarbituric acid) trimethine oxonol] stock solution was prepared in DMSO. Stock solution concentration was $20 \mathrm{mM}$. Cells were seeded in 96-well black wall plate and treated with 4-AP (4 mM), PTX (7.5 nM) and 4-AP (4 mM) + PTX (5 nM) for 24 hours. After treatment, medium was removed, cells were washed three times with HBSS and then resuspended with HBSS buffer containing 5 $\mu \mathrm{M} \mathrm{DiBaC} 4(3)$. Cells were incubated for $30 \mathrm{~min}$ at $37^{\circ} \mathrm{C}$ in $\mathrm{CO}_{2}$ incubator and then washed with HBSS to remove excess dye and incubated for another $30 \mathrm{~min}$ at $37^{\circ} \mathrm{C}$ in $\mathrm{CO}_{2}$ incubator. After incubation, fluorescence intensity was measured at excitation/emission: $485 / 520 \mathrm{~nm}$ wavelengths. In all cases, data was collected every $300 \mathrm{~s}$ for at least $45 \mathrm{~min}$ using the Kinetic program within the Gen5 software. Measurements were taken by Synergy $\mathrm{H} 1$ microplate reader (17).

\subsection{Cell cycle measurement}

Cell cycle assay was performed with quantitative immunocytochemistry to measure levels of Cdk2 protein phosphorylated Tyr15 (elevated in the G1/S arrest) and Histone H3 protein phosphorylated Ser10 (elevated in G2/M arrest) levels. Cells were seeded in 96-well black wall plate. Number of cells was 25.000 cell/well for MCF- 7 and 20.000 cell/well for L-929 in each well. Cell number was chosen according to doubling time of the cell and the well surface area. Cell cycle measurements were taken according to the manufacturer's kit protocol.

\subsection{Statistical analysis}

Results are expressed as mean value \pm standard deviation of mean $( \pm S D$ ). All experiments were analyzed by analysis of variance (ANOVA). A result with a $p$ value of $<0.05$ was considered statistically significant. 


\section{RESULTS}

\subsection{Cytotoxicity of 4-AP and PTX}

The purpose of this work was to determine if 4-AP would potentiate the effect of PTX on MCF-7 cell line and whether this combination would have a similar effect on L-929 cell line used as control. Since paclitaxel is known to cause adverse effects (18) we chose to use $\mathrm{IC}_{50}$ values and below. A synergistic effect would enable to use lower doses thus decrease the probability of side effects, of which the most serious is peripheral neuropathy. Initially $I_{50}$ values of each drug for both cell lines were determined. A combination of the two drugs each at $\mathrm{IC}_{50}$ values and also a combination at a slightly lower concentration of PTX was tested. In order to determine $\mathrm{IC}_{50}$ values MCF-7 and L-929 cells were incubated with various concentrations $(1,2,3,4,5 \mathrm{mM})$ of 4-AP and (1, 2, 3, 4, 5, 7.5 and $10 \mathrm{nM}$ ) PTX for 24 hours. IC $\mathrm{C}_{50}$ values were determined with trypan blue exclusion on haemocytometer. Previously, MTT and Alamar Blue (AB) assay were used however erroneous results giving false positive values were seen (19) and it was decided to make all measurements with trypan blue exclusion.

Fig. 1 and Fig. 2 shows the cell survival measurements made with various concentrations of PTX and 4-AP respectively. $\mathrm{IC}_{50}$ values for PTX treated cells were $7.5 \mathrm{nM}$ for both MCF-7 and L-929. These values are in accordance with the results of Liebmann et al. IC $\mathrm{C}_{50}$ value for 4-AP treated cells was $4 \mathrm{mM}$ for MCF-7 and $5 \mathrm{mM}$ for L-929 (20). Ru et al. detected the same $\mathrm{IC}_{50}$ values for the inhibition of cell proliferation for MCF-7 (21).

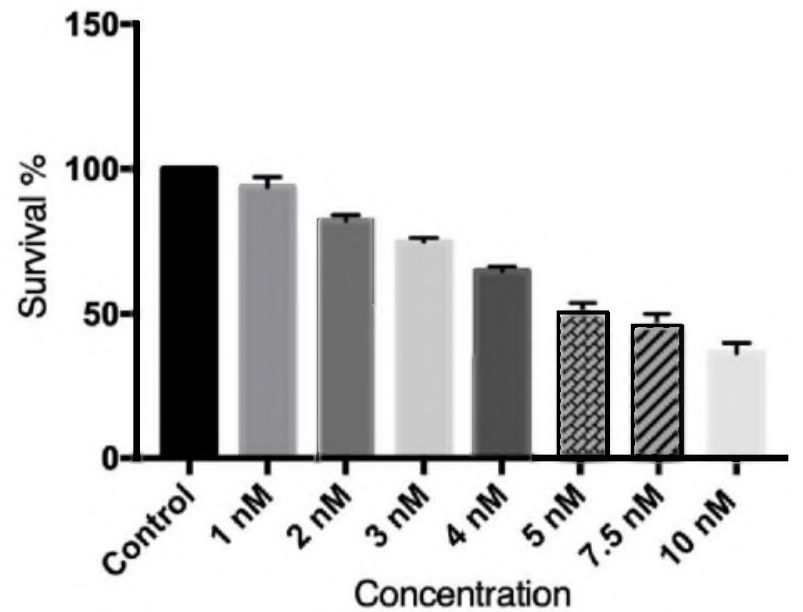

Figure 1a. Effects of PTX on L-929 survival

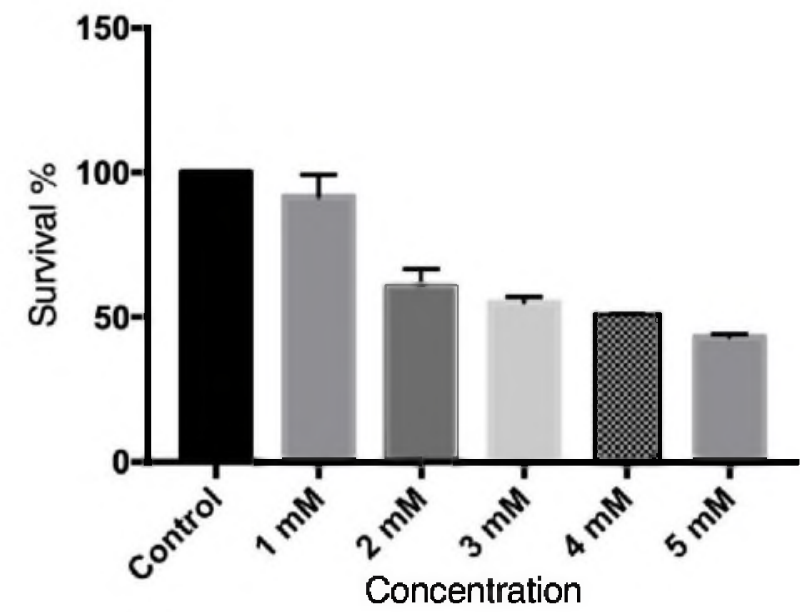

Figure 1b. Effects of 4-AP on L929 survival

Figure 1.a) Effects of PTX on L-929 survival. IC 50 value of PTX was determined for L-929. L-929 cells were treated with seven different concentrations of PTX for $24 \mathrm{~h}$ ( $37 \mathrm{C}, 5 \% \mathrm{CO}$ ). IC50 value was determined as $7.5 \mathrm{nM}$ for PTX (mean $\pm S D, n=3$ ). b) Effects of $4-A P$ on $L-929$ survival. IC50 value of 4-AP was determined for L-929. L-929 cells were treated with five different concentrations of 4-AP for $24 \mathrm{~h}$ $(37 C, 5 \%$ CO2). IC50 value was determined as $5 \mathrm{mM}$ for $4-A P$ (mean $\pm S D, n=3$ ).

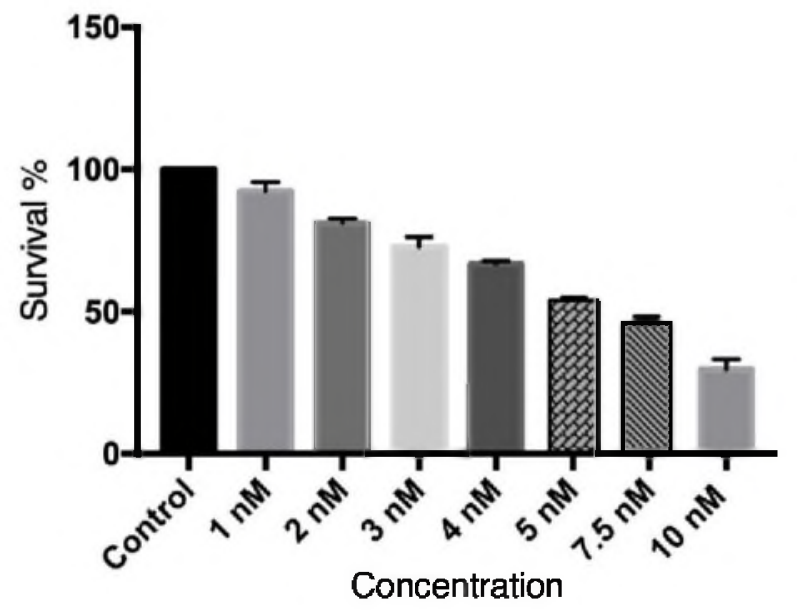

Figure 2a. Effects of PTX on MCF-7 survival

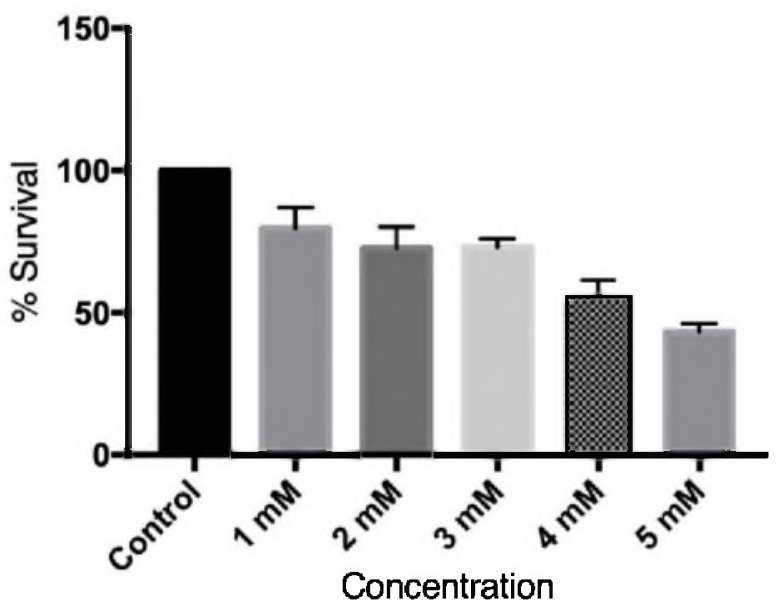

Figure $2 b$. Effects of 4-AP on MCF-7 survival

Figure 2.a) Effects of PTX on MCF-7 survival. IC50 value of PTX was determined for MCF-7. MCF 7 cells were treated with seven different concentrations of PTX for $24 \mathrm{~h}$ (37C, 5\% CO2). IC50 value was determined as $7.5 n M$ for PTX (mean $\pm S D, n=3)$. b) Effects of 4 - AP on MCF-7 survival. IC50 value of 4-AP was determined for MCF-7. MCF-7 cells were treated with five different concentrations of 4 -AP for $24 \mathrm{~h}(37 \mathrm{C}, 5 \% \mathrm{CO} 2)$. IC50 value was determined as $4 \mathrm{mM}$ for 4 -AP (mean $\pm S D, n=3$ ). 


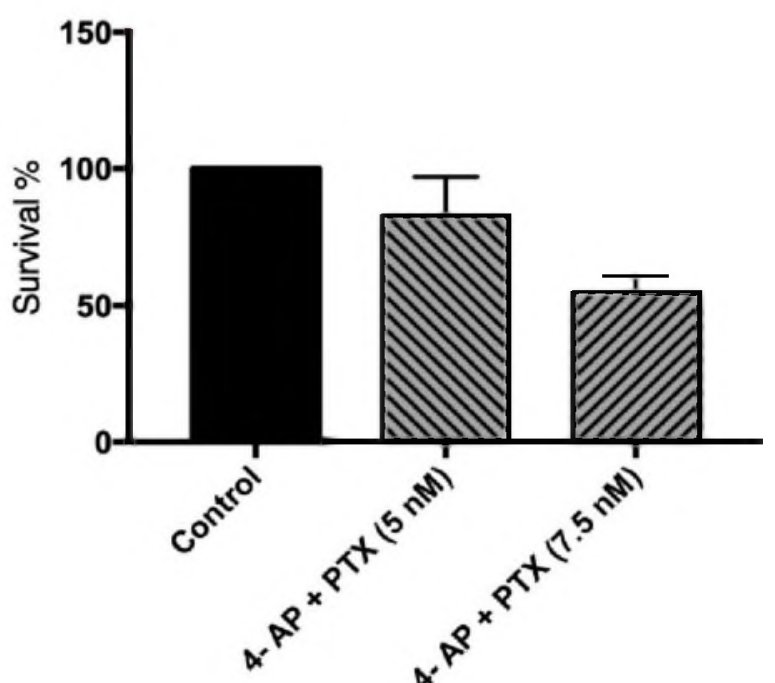

Figure 3a Effects of combination treatments on L-929 survival

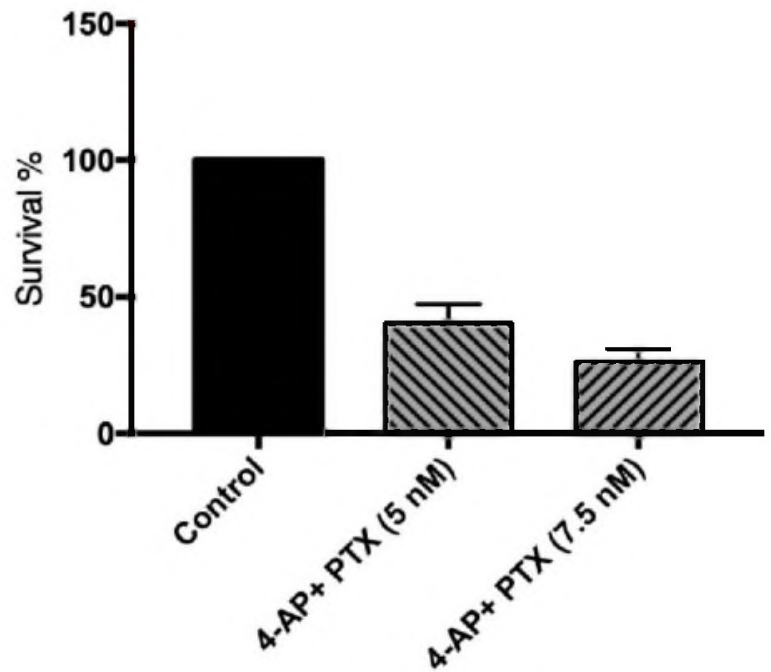

Figure 3b Effects of Combination treatments on MCF-7 survival

Figure 3.a) Effects of combination treatments on L-929 survival. L-929 cells were incubated with combination of 4-AP and PTX. 1. Combination: $4 \mathrm{mM}$ 4-AP+ $5 \mathrm{nM}$ PTX, 2. Combination: $4 \mathrm{mM} 4-A P+7.5 \mathrm{nM} P T X)$. After combination treatments survival was determined with trypan blue exclusion. (mean $\pm S D, n=3$ ). b) Effects of Combination treatments on MCF-7 survival. MCF 7 cells were incubated with combination of $4-A P$ and PTX (1. Combination: $4 \mathrm{mM} 4-A P+5 \mathrm{nM}$ PTX, 2. Combination: $4 \mathrm{mM} 4-\mathrm{AP}+7.5 \mathrm{nM}$ PTX). After combination treatments survival was determined with trypan blue exclusion. (mean \pm SD, $n=3$ ).

For combination treatment $\mathrm{IC}_{50}$ concentration of 4-AP $(4 \mathrm{mM})$ was chosen throughout. Two concentrations of paclitaxel were used for combination treatment that were deliberately chosen to be $\mathrm{IC}_{50}$ and a slightly lower concentration than PTX $\mathrm{IC}_{50}$ value.

Combination treatment of MCF-7 cell line resulted in a synergistic effect of 4-AP and PTX. 7.5 nM PTX and 4 mM 4-AP lowered the survival to $26 \% \pm 2.6$. When 4 -AP was combined with $5 \mathrm{nM}$ PTX, which by itself reduces the survival to $60 \%$ \pm 2.5 , the survival decreased to $40 \% \pm 3.7$. Combination treatments didn't have any synergistic effect on L-929 cells. On the contrary, the survival was seen to be about $80 \% \pm$ 8.08 even when $\mathrm{IC}_{50}$ concentrations were used in case of combination treatment (Fig. 3).

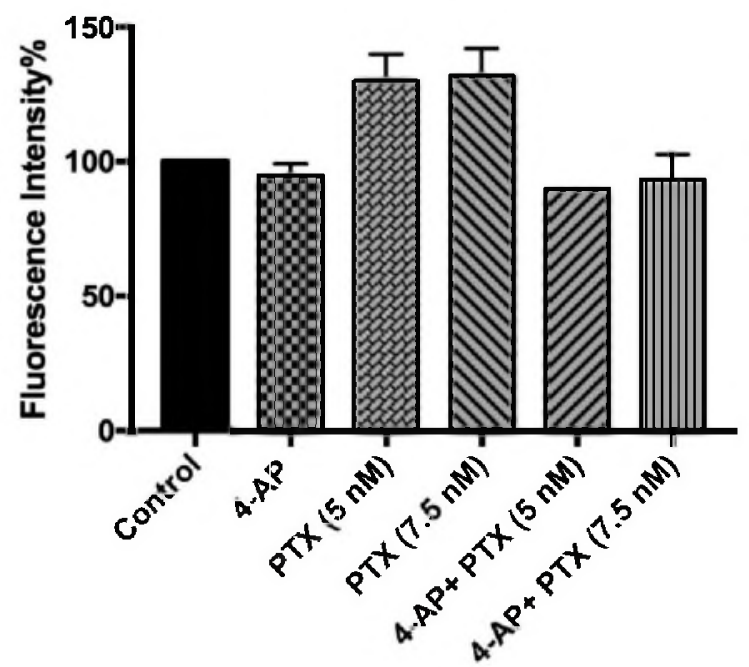

Figure 4a. Changes of Histone H3 levels for L-929

\subsection{Cell cycle analysis}

Phosphorylated Cdk2 Tyr15 and phosphorylated Histone H3 ser10 was determined using the cell cycle in cell Elisa kit. Phosphorylation of Cdk2 at Tyr15 indicates that it is inhibited and that a cell is at the G1/S transition. Phosphorylation of H3 at ser10 is tightly correlated with chromosome condensation during mitosis and a high level of $\mathrm{H} 3$ indicates that cells are mostly at the G2/M transition. So high Cdk2 with respect to control is indicative of a block at G1/S and a high H3 with respect to control is indicative of a block at $\mathrm{G} 2 / \mathrm{M}$.

Cdk2 and H3 levels were determined for 4-AP treatment, PTX treatment and combination treatments. For L-929 cells, there was no indication of G1 for 4-AP while PTX treatments seemed to arrest cells at G2/M. On the other hand, MCF 7 cells showed at G1 arrest in all treatments (Fig. 4 and Fig. 5).

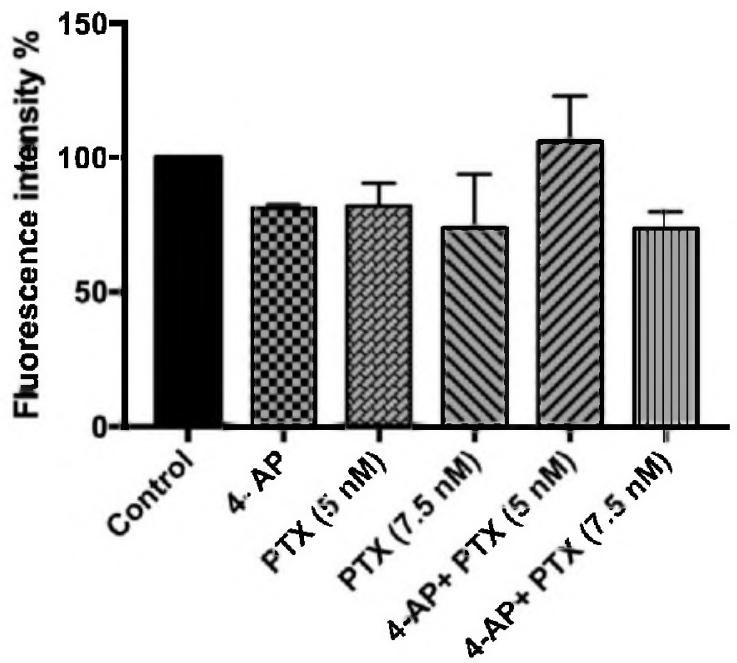

Figure 4b Changes of Histone $\mathrm{H} 3$ levels for MCF-7

Figure 4.a) Changes of Histone H3 levels for L-929 line. Cell cycle analysis was performed using cell cycle in cell Elisa kit by Fluorescent microplate reader. ( $p<0.05$ for all measurements, mean $\pm S D, n=3$ ). b) Changes of Histone $H 3$ levels for $M C F-7$ line. Cell cycle analysis was performed using cell cycle in cell Elisa kit by Fluorescent microplate reader. ( $p<0.05$ for all measurements, mean $\pm S D, n=3)$. 


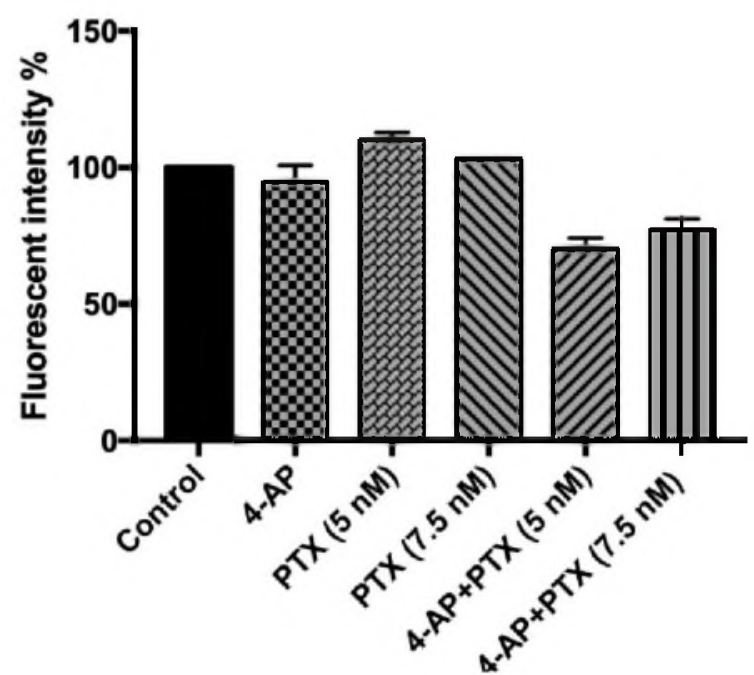

Figure 5a. Changes of Cdk2 levels for L-929

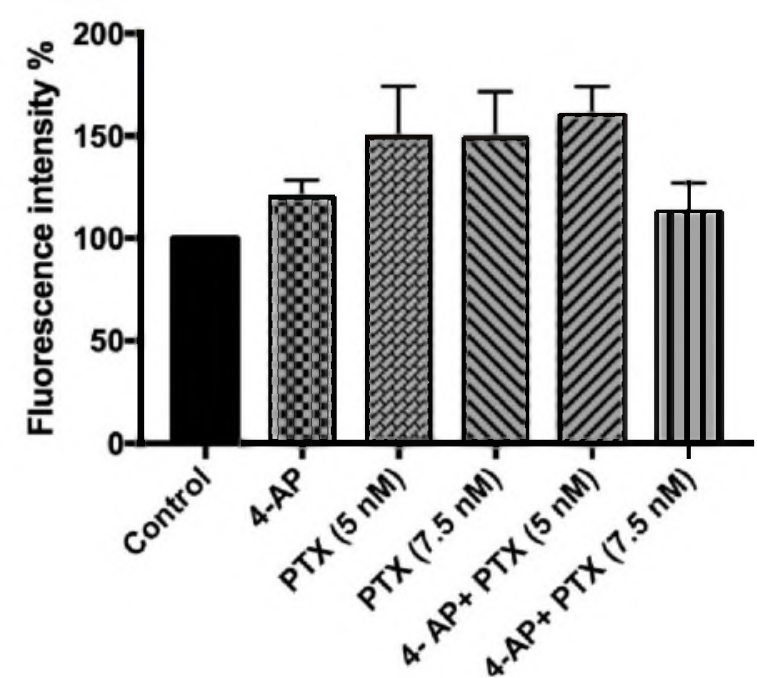

Figure 5b. Changes of Cdk2 levels for MCF-7

Figure 5. a) Changes of C $\mathrm{dk} 2$ levels for L-929 line. Cell cycle analysis was performed using cell cycle in cell Elisa kit by Fluorescent microplate reader. ( $p<0.05$ for all measurements, mean $\pm S D, n=3)$. b) Changes of Cdk2 levels for MCF-7 line. Cell cycle analysis was performed using cell cycle in cell Elisa kit by Fluorescent microplate reader. ( $p<0.05$ for all measurements, mean $\pm S D, n=3$ ).

\subsection{Plasma membrane potential measurements}

Plasma membrane potential changes were determined using $\mathrm{DiBaC} 4(3)$ fluorescent dye. When cell membrane potential is depolarized, dye enters into cell and fluorescence intensity increases. When cell membrane potential is hyperpolarized, dye cannot enter into cell and fluorescence intensity decreases. Plasma membrane potential changes were determined for 4-AP, PTX and combination treatments. For L-929 cell line, 4-AP, PTX ( $5 \mathrm{nM}$ and $7.5 \mathrm{nM}$ ) were seen to cause depolarization while combination treatments were seen to cause hyperpolarization. For MCF-7 cells, plasma membrane potential measurements resulted in depolarization for 4-AP, PTX (7.5 nM) and 4-AP + PTX (5 nM), and resulted in hyperpolarization for PTX $(5 \mathrm{nM})$ and 4-AP + PTX (7.5 nM) (Fig. 6).

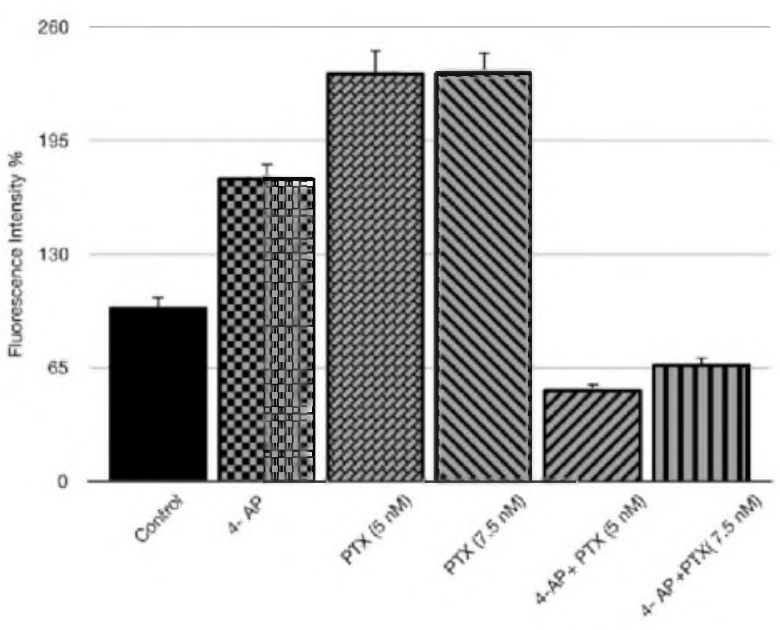

Figure 6a Changes of membrane potential for L-929

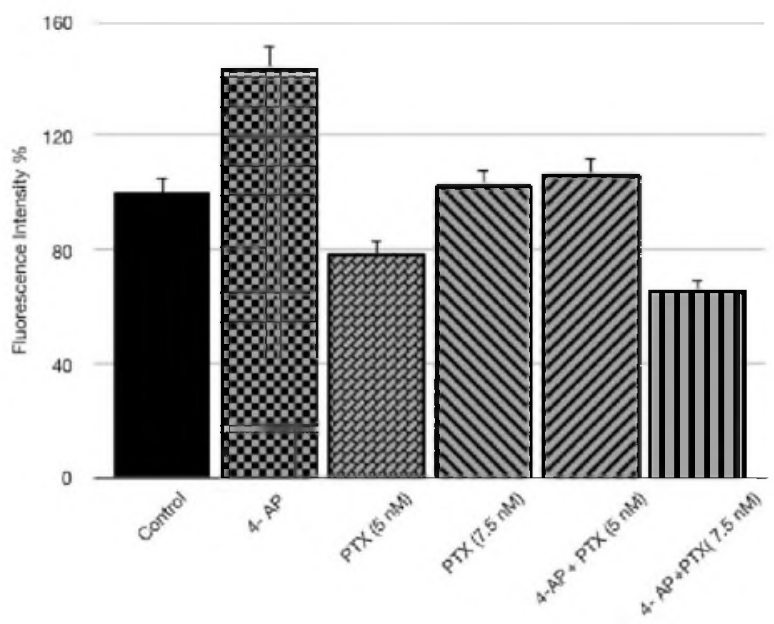

Figure $6 \mathrm{~b}$. Changes of membrane potential for MCF-7

Figure 6.a) Changes of plasma membrane potential for L-929. Membrane potential measurements were performed using DiBaC4(3) fluorescent dye by Fluorescent microplate reader. A decrease in intensity indicates hyperpolarization and an increase in intensity indicates depolarization with respect to untreated controls. ( $p<0.05$ for all measurements, mean $\pm S D, n=3$ ). b) Changes of plasma membrane potential for MCF-7. Membrane potential measurements were performed using DiBaC4(3) fluorescent dye by Fluorescent microplate reader. A decrease in intensity indicates hyperpolarization and an increase in intensity indicates depolarization with respect to untreated controls. $(p<0.05$ for all measurements, mean $\pm S D, n=3$ ). 


\section{DISCUSSION}

This work aimed to increase the effectiveness of paclitaxe on breast cancer cell line MCF-7 by a combination with 4-AP. Paclitaxel although used widely as a chemotherapeutic agent has some disadvantages limiting its use such as serious adverse effects like peripheral neuropathy, anemia, neutropenia, and hypotension and allergic reactions during the intravenous infusion (4). Apart from this, as in the case of any chemotherapeutic agent multiple drug resistance is observed. Paclitaxel resistance is seen to be caused by overexpression of multidrug resistance (MDR-1) gene, molecular changes in the target molecule (which is tubulin), changes in apoptotic regulatory and mitosis checkpoint proteins, and changes in lipid composition (22). Due to these facts, paclitaxel has frequently been used in combination with other chemotherapeutic agents (23).

The rationale for the choice of 4-aminopyridine is as follows. It is generally accepted that paclitaxel arrests the cell at $\mathrm{G} 2 / \mathrm{M}$ and it is reasonable to assume that cell death is due to mitotic arrest. However mitotic arrest results in either death or exit from mitosis without chromosome segregation or cytokinesis forming a tetraploid G1 cell. This is known as mitotic slippage. After slippage, cells can enter another cycle or arrest or die. We reasoned that in the case of a mitotic slippage which is seen to occur in case of paclitaxel - a drug that would arrest cell cycle at G1 phase - would increase the effectiveness of paclitaxel $(24,25)$. On the other hand Zasadil et al. showed that patient tumors treated with paclitaxel exhibited multipolar spindles, and they suggested that paclitaxel mediated cell death in patient tumors is due to chromosome missegregation on abnormal mitotic spindles rather than mitotic arrest (26). In either way that is either due to mitotic slippage or formation of multipolar spindles and arrest at G1 should be seen. Our results are in accordance with these views.

We deliberately chose the $I C_{50}$ concentration of paclitaxel and one concentration below $I C_{50}$ to be able to determine if a probable synergistic effect was dose dependent. The survival for MCF-7 decreased to $40 \%$ and $26 \%$, respectively indicating that the effect of combination treatment was dependent on dosages used. Interestingly these combinations did not have any effect on L-929 cell line which is the non-cancerous fibroblast cell line often used in cancer pharmaceutical research.

For MCF 7 cells, Cdk2 and H3 measurements showed that with 4-AP treatment cells were arrested at G1 phase as expected. On the other hand, paclitaxel treated cells were seen to have Cdk2 values which indicates that cells were mostly at G1 phase. Pushkarev et al., upon a cell cycle analysis with low doses of paclitaxel observed that most cells were in $\mathrm{G} 1$ and subG1 phase (27). Also, Cdk2 and H3 values indicated that combination therapy caused cell death mostly at $\mathrm{G} 1$ phase of cell cycle. Whether these cell are tetraploid needs to be confirmed by imaging techniques.
Interestingly, Cdk2 values of 4-AP treated L-929 cells were same as those of the control, suggesting that cells were not arrested at G1 phase. This seems to contradict with previous reports that indicate a G1 arrest after 4-AP treatment. It is probable that 4-AP exerts its function to healthy and cancerous cells differently since it has been documented that $\mathrm{K}^{+}$channel expression in malignant cells is altered (28).

Plasma membrane potential measurements for MCF-7 cells showed that paclitaxel caused hyperpolarization at $5 \mathrm{nM}$ while it caused a slight and statistically insignificant depolarization at $7.5 \mathrm{nM}$ which is the $\mathrm{IC}_{50}$ value. Combination treatment caused a hyperpolarizing effect for both $5 \mathrm{nM}$ and $7.5 \mathrm{nM}$ paclitaxel concentrations. It seems that paclitaxel suppressed the depolarizing effect of 4-AP. L-929 showed that 4-AP and paclitaxel caused depolarization at single treatments with respect to untreated cells while combination treatment caused hyperpolarization. These results indicate that a change in plasma membrane potential cannot be correlated with survival unless cell type specific ion channel expressions and current measurements are made since it is well known that cancerous cells have a more depolarized membrane potential and ion channel expression $(7,15)$. These observations also necessitate kinetic measurements of membrane potential during the course of incubation.

\section{CONCLUSION}

Overall, these results provide evidence that 4-AP acted synergistically with paclitaxel on MCF-7 cells and makes this combination a promising treatment for breast cancer.

Acknowledgements: This study was supported by the Marmara University Scientific Research Project Department (SAG-C-DRP - 080.715.0327).

We thank Assoc. Prof Oya Orun for kindly supplying the cell lines and MSc. student PInar lyiol for assisting the laboratory work.

\section{REFERENCES}

[1] Sharma GN, Dave R, Sanadya J, Sharma P, Sharma KK. Various Types and Management of Breast Cancer: an Overview. J Adv Pharm Technol Res 2010; 1(2): 109-126.

[2] Waks AG, Winer EP. Breast Cancer Treatment a Review. JAMA 2019; 321(3):288-300.

[3] Walsh V, Goodman J. The billion dollar molecule: Taxol in historical and theoretical perspective. Clio Med 2002; 66: 245267.

[4] Erdemoğlu N, Şener B. Taksan Sınıfı Bileşiklerin Antitümör Etkileri. Ankara Ecz. Fak. Derg 2000; 29(1): 77-90 (Turkish)

[5] Jordan MA, Wilson L. Microtubules as a target for anticancer drugs. Nat Rev Cancer 2004; 4(4): 253-265.

[6] Weaver BA. How Taxol/paclitaxel kills cancer cells. Mol Biol Cell 2014;25(18): 2677-2681.

[7] Bates E. Ion Channels in Development and Cancer. Annual Review of Cell and Developmental Biology 2015; 31(1): 231247. 
[8] Comes N, Serrano-Albarrás A, Capera J, Serrano-Novillo C, Condom E, Ramón y Cajal S, Ferreres JC, Felipe A. Involvement of potassium channels in the progression of cancer to a more malignant phenotype. Biochim. Biophys. Acta Biomembr. 2015; 1848: 2477-2492.

[9] Jensen JM, Shi R. Effects of 4-aminopyridine on stretched mammalian spinal cord: the role of potassium channels in axonal conduction. J Neurophysiol 2003 Oct; 90(4): 2334 2340.

[10] Wang W, Fan Y, Wang S, et al. Effects of voltage-gated K+ channel on cell proliferation in multiple myeloma. Scientific World Journal. 2014; 2014:785140. doi:10.1155/2014/785140

[11] Kim JA, Kang YS, Jung MW, Kang GH, Lee SH, Lee YS. Ca2+ influx mediates apoptosis induced by 4-aminopyridine, a $\mathrm{K}+$ channel blocker, in HepG2 human hepatoblastoma cells. Pharmacology 2000 Feb; 60(2): 74-81.

[12] Wang W, Xiao J, Adachi M, Liu Z, Zhou J. 4-aminopyridine Induces Apoptosis of Human Acute Myeloid Leukemia Cells via Increasing [Ca2+] i Through P2 X7 Receptor Pathway. Cell Physiol Biochem 2011; 28: 199-208.

[13] Hu CL, Liu Z, Zeng XM, Liu ZQ, Chen XH, Zhang ZH, Mei YA 4-Aminopyridine, a Kv channel antagonist, prevents apoptosis of rat cerebellar granule neurons. Neuropharmacology 2006; 51: 737-746.

[14] Barghouth PG, Thiruvalluvan M, Oviedo NJ. Bioelectrica regulation of cell cycle and the planarian model system. Biochimica et Biophysica Acta 2015;1848: 2629-2637.

[15] Sundelacruz S, Levin M, Kaplan DL. Role of Membrane Potential in the Regulation of Cell Proliferation and Differentiation. Stem Cell Rev 2009; 5(3): 231-46.

[16] Jordan MA, Wendell K, Gardiner S, Derry BW, Copp H, Wilson L. Mitotic Block Induced in HeLa Cells by Low Concentrations of Paclitaxel Results in Abnormal Mitotic Exit and Apoptotic Cell Death. Cancer Research 1996 ;56(15): 816-825.

[17] Gopalakrishnan M, Buckner SA, Whiteaker KL, Shieh $\mathrm{CC}$, et al. (-) - (9S)-9-(3-Bromo-4-fluorophenyl)2,3,5,6,7,9-hexahydrothieno[3,2-b] quinolin-8(4H)-one 1,1-Dioxide(A-278637): A Novel ATP-Sensitive Potassium Channel Opener Efficacious in Suppressing Urinary Bladder Contractions.I. In Vitro Characterization. The Journal of
Pharmacology and Experimental Therapeutics 2002; 303:379386.

[18] Marupudi NI, Han JE, Li KW, Renard VM, Tyler BM, Brem H. Paclitaxel: A Review of Adverse Toxicity and Novel Delivery Strategies. Expert Opinion on Drug Safety 2007;6: 609-621.

[19] Ulukaya E, Ozdikicioglu F, Yilmaztepe Oral A, Demirci M. The MTT assay yields a relatively lower result of growth inhibition than the ATP assay depending on the chemotherapeutic drugs tested. Toxicology in Vitro 2008;22: 232-239.

[20] 20. Liebmann JE, Cook JA, Lipschultz C, Teague D, Fisher J, Mitchell JB. Cytotoxicity Studies of Paclitaxel (Taxol) in Human Tumor Cell Lines. Br. J. Cancer 1993; 68: 1104-1109.

[21] Ru Q, Tian X, Liu JS, Li CY. 4 - Aminopyridine İnhibits Cell Proliferation and Affects Anti-Tumor Activities of Cell Cycle Specific Drugs. In: Chou JJ, Zhou H, editors. Proceedings of The $9^{\text {TH }}$ International Conference on Bioinformatics and Biomedical Engineering; 2015 Sept 18-20; Shanghai, China. Taylor \&Francis Group, UK: London. 2016; 383-408.

[22] Yusuf RZ, Duan Z, Lamendola DE, Penson RT, Seiden MV. Paclitaxel Resistance: Molecular Mechanisms and Pharmacologic Manipulation. Current Cancer Drug Targets 2003; 3: 1-19.

[23] Yardley DA. Drug Resistance and the Role of Combination Chemotherapy in Improving Patient Outcomes. International Journal of Breast Cancer 2013;1: 1-15.

[24] Sinha D, Pascal HG, Khanna D, Khanna KK. Mitotic slippage: an old tale with a new twist. Cell Cycle 2019; 18:1: 7-15.

[25] Henriques AC, Ribeiro D, Pedrosa J, Sarmento B, Silva PMA, Bousbaa $\mathrm{H}$. Mitosis inhibitors in anticancer therapy: when blocking the exit becomes a solution. Cancer Lett. 2019; 440: 64-68.

[26] Zasadil LM, Andersen KA, Yeum D, etal. Cytotoxicity of paclitaxel in breast cancer is due to chromosome missegregation on multipolar spindles. Sci Transl Med. 2014;6(229):229-243.

[27] Pushkarev VM, Starenki DV, Saenko VA, Yamashita S, Kovzun OI, Popadiuk ID, Pushkarev VV, Tronko MD. Effects of low and high concentrations of antitumour drug taxol in anaplastic thyroid cancer cells. Experimental Oncology 2009; 31:16-21.

[28] 28. Huang $X$, Jan LY. Targeting potassium channels in cancer. J Cell Biol. 2014;206(2):151-162. 